\title{
Analysis on the Current Situation and Problems of the Training Mode of Thai Language Professionals in Yunnan Higher Education Institutions -- Analysis on the Talent Training Model Combining Professional Teaching with Overseas Learning and Practical Training
}

\author{
Ya Liang*, Yi He, Mengjia Hou and Ling Yang \\ Yunnan College of Foreign Affairs \& Foreign Languages, Yang Lin 651700
}

Keywords: Yunnan University; Thai Language teaching; Overseas training; Development opportunities; Training mode

\begin{abstract}
In recent years, with the implementation of the development strategy of "One Belt And One Road" and the deepening of exchanges between China and Thailand, the number of institutions of higher learning in Yunnan for the Thai language major has been increasing. Demand for Thai talent demand at home and abroad to intensify efforts to cultivate professional talents in colleges and universities and international talents, so colleges and universities in Yunnan Thai professional talent training mainly adopts the model of combining teaching with study abroad training. From the training mode of open Thai professional colleges and universities in Yunnan province present situation and problem analysis, Thai, training opportunities and necessary for the development of talent training mode reform of colleges and universities in Yunnan province Thai professional personnel training mode is analyzed.

The necessity of talent cultivation in combination with the professional teaching of Thai language and the practical training of overseas learning in Yunnan higher education institutions.

This paper is funded by the Yunnan provincial education department's scientific research project. A probe into the talent training mode of combining the professional teaching of Thai language with the practical training of overseas learning in higher vocational colleges. Subject no. 2017ZDX289
\end{abstract}

\section{Background and Current Situation of Setting up Thai Language Major in Yunnan Province}

Since 2013, Xi Jinping, chairman of the "area", "South Asia, southeast Asia radiation center", under the leading the drive for economic development, Yunnan has become a frontier of China - Asean free trade area and the hub, and the asean free trade area and the LanCang river and Mekong subregion. Education, a higher education institution in Yunnan province, has both geographical advantages and complementary resources for running cooperative schools in southeast Asia. On the one hand, Yunnan is superior to myanmar, Vietnam and other southeast Asian countries in terms of economic and social status and education level, which is conducive to Yunnan's export of culture. Yunnan is rich in resources, on the other hand, for Yunnan higher education research in many disciplines, especially natural discipline, such as agriculture, forestry, fishery and other professional can completely fill the lack of talents in these countries. Yunnan multi-ethnic communal integration with its neighboring countries, made as the higher education in Yunnan and the surrounding neighbors of higher education are facing the same problem, namely, higher education of minority nationalities, the similar case that Yunnan and around southeast Asian countries have a similar education foundation.

Since January 1, 2010, China launched a asean free trade area, the response strategy of "going out" in Yunnan province in recent years, Yunnan province, as an important "bridgehead" country open to the southwest, is the country to speed up and southeast Asia and South Asia countries important channel of the development of politics, economy, culture and education, in order to meet 
the need of the development of the country, and Yunnan, GuangXi terrain advantage, make each college appear ostasiatischen seminar language, especially Thai. In this context, most universities and vocational schools in Yunnan, both public and private, have started teaching Thai.

In recent years, with China and deepen communication, open a Thai professional colleges and universities in Yunnan province, according to data show that in 2012, Yunnan Thai courses in colleges and universities has more than 30, more than 4000 Thai students learning, Thai students had joined English has the largest number of foreign language learning. With the deepening of trade between China and Thailand, Yunnan's demand for Thai language talents has increased dramatically. Therefore, increasing the training of specialists in the field of Thai in Yunnan province and inter-disciplinary talent, set up the Thai language and culture center of Yunnan normal university, Yunnan nationalities university set up a southeast Asian language and culture school, visible, the necessity to open such a Thai professional in Yunnan.

Yunnan University of Nationalities. Thai professional subordinate institute of south east Asia, southeast Asia college is approved by the provincial government of "talent training base" in Yunnan province, China - Asean language culture, the general language of the college undergraduate course has the ideal condition of running and a long history of running. After nearly 20 years of construction, March 2017, the institute of southeast Asia has become the local colleges in the ministry of education approval to open a lingua franca type undergraduate quantity top, with the cultivation of the master's degree award authority unit level subjects. The school also has two national quality engineering projects, namely "non-lingua franca population" national specialty, "basic Thai language" national quality courses and 14 provincial quality engineering projects.

Yunnan Normal University. Education college of international Chinese offers a Thai language major, which is a non-normal undergraduate major. It implements the " $2+\mathrm{N}+\mathrm{N}$ " mode of cultivating small language talents. The Chinese language institute also offers a Thai language major, which adopts the "2+N+N" small language talent training mode. During the four years of college, apart from learning the language of small languages, students can strengthen their English courses and become practical talents of "small languages + English + professional skills".

Yunnan Agricultural University. Thai, professional set up in 2014, with $2+1+1$ training mode, after graduation can be in foreign affairs, tourism, trade, culture, press and publication, education and other departments skillfully use Thai, is engaged in the economic and cultural exchange, translation, research, education and management.

Yunnan Tourism Vocational College. Applied Thai professional foreign languages department, focus on training in foreign affairs, foreign enterprise, tourism, trade, culture and education departments can skillfully use Thai, is engaged in the economic and cultural exchange, translation, research and management, education and other work applied and special talents.

Yunnan Vocational College of Foreign Affairs in Economy and Trade. Yunnan economic and trade affairs Thai professional vocational college application and Chiang Mai, Thailand university joint cooperation of $2+1$, namely Yunnan economic and trade vocational college students in charge of foreign affairs at the completion of the first two years in Yunnan province economic and trade vocational college in charge of foreign affairs after the professional learning, in the third year of college will provide opportunities for students to study in Chiang Mai university for further study.

Yunnan College of Foreign Affairs and Foreign Languages. Yunnan institute of foreign affairs in a foreign language professional applied Thai as support professional language classes in colle ge, students are required to study synchronization with qualification examination, original favored by unit of choose and employ persons "foreign language + professional + skills" of the compound and practical professional foreign talent cultivation model. At the same time, the school adhere to the "to adapt to the social economic development demand as the guidance, cultivating high comprehensive quality, solid professional basis, professional skilled, strong practical ability, have the international perspective, the feelings and the ability to cross-cultural communication" applied talents ".

Application Thai professional training to meet the need of socialist modernization construction, the morality, intelligence and physique, us, fatigue all-round development, to master the necessary professional theory and strong practice operation skill, with solid Thai language and culture 
foundation and some asean regional trading nation language and culture ability, meet the tourism, trade, a line of Thai language needs of high-quality skilled personnel and asean countries. Our short - and long-term cooperation project is established in several institutes of higher learning with Thailand, one of the most important is the north garden royal university established the Thai language and culture center in our university, to the training of specialists in the field of Thai, efforts to cooperate with Yunnan layout along the "area", strive to build a radiation center for south southeast Asia's strategic development target, set up "foreign language + professional training + overseas internship recommend overseas employment" the green channel of talents cultivation, can ensure that cooperation is efficient for a long time, really develop the internationalization of skilled talents to adapt to the social demand.

\section{Curriculum setting of Applied Thai Language Major in Yunnan University.}

Application of Thai professional courses: basic Thai, Thai, listening, spoken Thai, Thai, Thai, writing, reading, and Thai grammar, senior Thai, Thai Chinese translation, Thai, Thai newspaper reader, tourism, etc.

Professional focus has a solid Thai language elementary knowledge and the economic and trade, tourism knowledge and skills, has the strong practice ability, can be in foreign affairs, trade, tourism, culture, education, business and other departments engaged in translation, a tour guide, business negotiations, teaching and management of Thai applied talents. Existing teaching and training modes of Thai language major and overseas learning in Yunnan province

Currently in Yunnan and Thailand cooperation in running schools adopt the "2 + 2", "3 + 1" mode is more, the students accomplish a certain number of studies at home, abroad asked to accomplish a certain number of academic and at the same time have a degree in domestic universities and foreign universities, sometimes also used by teachers on a regular basis to outside Chinese teaching to the student, accomplish a certain number of academic degrees. Secondly, education mode of cross-border higher education is mainly represented by the following three forms: independent running by foreign church institutions in China, overseas running by China and joint running by Chinese and foreign universities. Cross-border higher education education mode of running schools is relatively flexible and has relatively small restrictions on running schools. At present, many domestic universities adopt this mode of running schools.

\section{Problems and Development Opportunities Exist in the Talent Training Mode of Combining the Professional Teaching of Thai Language with Overseas Practical Training in Yunnan Higher Education Institutions.}

From 2002 since the launch of the China-Asean free trade area for cooperation in the field of higher education has been moving forward, signed in 2002 "China-Asean framework agreement on comprehensive economic cooperation", the human resources development as the five priority areas to strengthen cooperation; The action plan for implementing the joint declaration on China-Asean strategic partnership for peace and prosperity, signed in 2004, has also been mentioned in the forefront of strategic development. Signed in 2006 with the China-Asean commemorative summit in the joint statement pointed out that to strengthen the social and cultural cooperation and encourages greater cooperation between both secondary and higher education institutions, to set up the China - Asean honorary fellowship, strengthen academic exchanges, and education aspects of cooperation. Yunnan provincial medium - and long-term education reform and development planning outline (2010-2020), "pointed out that after 5 to 10 years of efforts, built" one park three platforms ", namely, home to the international education, international education infrastructure platform, international education personnel training platform, international education exchange and cooperation platform. With the support of the national policy, education in Yunnan province is developing better and better in the communication with southeast Asia.

Yunnan normal university, the association of south-east Asian nations international college and Lan Cang - Mekong subregion of human resource development center, Yunnan university for 
nationalities, Yunnan university international language institute and the association of south-east Asian nations research center of China - Asean education training center of teaching and research institutions, such as, are designed to focus on training for the association of south-east Asian nations in international economic and trade and tourism management talents, master of international Chinese teachers, Chinese international promotion, etc., in the process of higher education cooperation and exchange for southeast Asia, continuously explore ways of cooperation, in order to realize the all-round cooperation, more communication results.

Higher education of Yunnan higher education facing southeast Asia cooperation have achieved good results at present, most colleges and universities at all levels in Yunnan province and asean countries signed an agreement of cooperation in running schools in colleges and universities, through various forms to carry out the higher education cooperation in running schools. From the current higher education in Yunnan province for the main form of cooperation in southeast Asia, mainly divided into the following kinds: To Yunnan education for international students, through the guidance of government scholarship, there have been more and more southeast Asian students to study abroad for further study at universities in Yunnan province; Higher education resources are introduced, including the study data, video and audio and video materials, teaching materials, in addition to material resources, human money at colleges and universities also introduce the foreign teachers, everything is in order to improve the quality of teaching and scientific research;To go abroad to study, train the internationalized talents, through the professional study way, local projects and other transport communicate study in Chinese teaching to southeast Asia, in order to cultivate familiar with familiar with southeast Asia regional exchanges and cooperation of talents; Promoting Chinese, many colleges and universities in Yunnan province are set up a system of teaching Chinese as a foreign language courses for students, including Yunnan university also set up Chinese international education master's degree; Chinese-foreign cooperation in running schools, to carry out international cooperation projects, from the humanities to science cooperation projects are involved, such as the establishment of china-asean education training center of Yunnan agricultural university, Kunming university of science and technology and Laos joint training MBA high-level talents, etc. Thebranding effect of cooperative education brings opportunities to Yunnan universities and cooperative schools.

As of April 15, 2015, Yunnan china-Thailand cooperative education institutions and China-Thailand cooperative education programs are as follows:

In terms of Chinese education, one is by Yunnan sending Chinese teachers of colleges and universities, and in southeast Asian countries to establish Confucius institute, Chinese language and culture center and Yunnan normal university in 2005 to become the first overseas to undertake one of 16 universities of the university of Confucius. Foreign students education of colleges and universities in Yunnan province, on the other hand, had a bigger development, Yunnan university, Yunnan normal university, Yunnan university of finance and economics and so on six colleges and universities, not only in the Chinese system of teaching courses to international students, foreign students and carry out the record of formal schooling education, various forms of studying abroad and to Yunnan study abroad is increasing.

Is temporarily no and southeast Asian countries cooperation in running schools, on the one hand is the mode of cooperation in running schools did not in the actual operation of southeast Asian nations, there is no mature experience of running school, on the other hand, if the mutual recognition of the qualification certification and international quality evaluation of higher education, there is no peer mode of education system.

In addition, the education resources from people on both sides of the cooperation in running schools school, teaching conditions, teaching effects and so on many ways, the Yunnan university and school of foreign cooperation in running schools in the above aspects are better than Yunnan has advantages of colleges and universities, students choose professional cooperation in running schools, one of the main reason is that I hope to receive a better education abroad, but from the overall situation of education of southeast Asian nations, countries vary in the development of higher education, higher education is relatively good, but Thailand has a perfect education system, 
such as Chulalongkorn University, University of Malaya, the Philippines University and the University of Jakarta, the national institutions of higher learning, With its long history and relatively developed economy, it can also compete with Yunnan university.

Third, the reform and development path of the talent training mode of combining the professional teaching of Thai language with overseas practical training in Yunnan higher education institutions

Region of Yunnan province has a good location, and diverse ethnic culture, beautiful scenery, and has the congenital advantage of the development of foreign students education career, at the same time, the development of students, education career to improve cultural soft power, in Yunnan province is of great significance to promote the internationalization of Yunnan province, Yunnan education of international students work is mainly composed of colleges and universities, college also successively carried out the study abroad programs in recent years, for learning of Thai students more and more of the platform and opportunity.

Continues to increase at one's own expenses study abroad in recent years, the number of southeast Asian nations become Yunnan students choose to go abroad, study abroad were rising year by year in Yunnan province, and presents the phenomenon of early onset, studying the market demand is more and more big, according to incomplete statistics, there are about 5000 people a year in our province to study abroad, the increment amplitude will be about $20 \%$ every year.

Yunnan is located in southwest China and is connected with many countries in southeast Asia by mountains and waters. In recent years, through the implementation of education in our province "going out" plan, set up "the government of yYunnan province to recruit surrounding countries foreign student scholarship", make the accelerating internationalization of education, and further enhance the international influence. According to statistics, the province's 68 colleges and universities have different degree and southeast Asian countries to carry out the education exchanges and cooperation, with more than 50 countries and regions and education organizations to establish the cooperation education, and set up 11 international talent training base, 8 Confucius institutes and 56 small language public foreign language teaching and research section. Since 2011, the number of students studying in Yunnan has exceeded 20,000,60\% of them from neighboring countries.

Problems Existing in The talent Training Mode of Combining the Professional Teaching of Thai Language with Overseas Practical Training in Yunnan Higher Education Institutions. First of all, education of Yunnan university is not innovative enough for international cooperation in running schools in southeast Asia. Starting from the view of international cooperation in running schools, to achieve success in the true sense, international cooperation in running schools should be in line with the four principles: cooperative education internationalization, marketization, rationalization, diversification, go hand in hand, only the four aspects is likely to create a brand effect of the cooperation in running schools reputation, also can attract more students in China and the association of southeast Asian nations. If simply rising to a certain value as an index for judging the success of international cooperation in running schools, such as higher education in Yunnan and the increase of the number of the university cooperation projects of southeast Asian nations, or bilateral students interact with one another numerical growth, perfect significantly.

From the perspective of educational internationalization, the most important criterion to judge the success of cooperative education is the improvement of educational quality. From the current higher education in Yunnan and southeast Asia international cooperation in running schools in the achievements, on the one hand, Yunnan's higher education faces the less-developed countries single output of higher education resources, such as Yunnan higher education subjects in the study of natural science to southeast Asian countries to cultivate more talents, but the association of southeast Asian nations has the advantage of financial, social science and other disciplines of higher education in Yunnan province and the cooperation of the strength is enough. Yunnan, on the other hand, higher education and the more developed southeast Asia international cooperation in running schools due to its economic strength is insufficient, on the overall construction of higher education is impossible, by contrast, showed a trend of passive in the cooperation. 
From the perspective of education marketization, at present of Yunnan higher education facing southeast Asian countries cooperation in running schools are mainly concentrated in cooperation with university of southeast Asia countries, from the market point of view, the education market in addition to the cooperation between colleges and universities there are a lot of opportunities, such as the cooperation between colleges and the government and the school cooperation and so on the many kinds of possibility, how the cooperation in running schools of tentacles into all aspects of Yunnan higher education and the southeast Asia area, makes the education geared to the needs of market choice, either from the aspect of national culture, and folk culture level have to be involved, this will give Yunnan's higher education brings new opportunity.

From the rational point of view, as the higher education in Yunnan and southeast Asian country's higher education, is to have a clear understanding of their own education resources, and in view of the planning design to the respective features of different periods, including short-term and long-term, mid-term and long-term, to the international education cooperation in running schools project to the upward trend in progressive development, and their education system, education system, credit certification of carefully for both sides is debatable reciprocity mechanism of international cooperation in running schools, improve the cooperation pattern. Higher education from the perspective of educational diversity, Yunnan needs on the basis of traditional advantage disciplines, in view of the higher education in southeast Asia market, uninterrupted launched project for the region, to attract more foreign students, foreign cooperation in running schools and stable, long-term cooperation basis. On the basis of constantly consolidating and expanding the traditional advantage projects, Yunnan university will mobilize the enthusiasm and education advantage to build a new education brand project.

Secondly, the teaching effect of education needs to be enhanced. Yunnan higher education education's cooperative education for southeast Asian countries was originally intended to attract more overseas students to study in China and spread the advantages of education resources abroad. From the present teaching situation, the number of southeast Asian students to receive higher education in Yunnan in increase year by year, caused by a lack of development on students management work, students self-study consciousness is not strong, the end of the study in learning the effect not beautiful. For this kind of situation, on the one hand is to use the effective incentive measures, attract more students to expand to Yunnan on the basis of study of higher education students, incentives to promote the students learning, strengthen students learning effect. On the other hand, education should be adopted to change the concept of overseas students, correct their attitude towards studying abroad, put learning in the first place, and create an environment conducive to cross-cultural communication.

Finally, cultivate talents suitable for asean regional development. A universal problem throughout China's current higher education, the popularization and homogeneity becomes common, in Yunnan province in the southwest of the geographical position, its education level in the whole education in colleges and universities in China in the comparison of the position, so Yunnan higher education compared with the developed areas of China's higher education, more problems, such as lack of education, of which the most obvious to the lack of overseas elite talent, but there is no denying the fact that overseas elite education experts in international cooperation in running schools play a role in the communication is very important, if you want to in southeast Asia as the dominant force in cooperation in running schools of higher education, Yunnan's higher education to do a characteristic in view of the existing advantages, more should consider running results, from the perspective of practical talents, in view of the actual state of the southeast Asian countries, in order to market demand as the guidance, research needs talent gap in development among regions, cultivate suitable for both can satisfy the south-east Asia region development and compound talents with the internationalization.

With the development of economic globalization trend, Yunnan from China southwest provinces become oriented to the forefront of asean countries, higher education in Yunnan in this form to toward education internationalization, strive for more cooperation and communication in South Asia, southeast Asia and other regions educational opportunities, suitable for economic development so as 
to cultivate talents. Especially "neighbourhood" cooperation development idea is put forward, should make full use of Yunnan advantageous geographical position with its neighboring countries, mutual benefit, win-win co-prosperity, so only to realize the higher education in Yunnan for southeast Asia cooperation in running schools present situation and problems of the communication, can be targeted to improve and make greater achievements.

Advantages of the Talent Training Mode of Combining the Teaching of Thai Language Major with Overseas Practical Training in Yunnan Higher Education Institutions. Thailand's education quality has been recognized by the international examination agency, Thailand's higher education in the curriculum, education method and education system adopts the model of the European and American countries, the study in Thailand has its unique advantages: National advantages. Thailand is a ritualistic country. Foreigners are treated equally and friendly in Thailand. There are even special tourist police to protect the safety and rights of foreigners. Eastern and western cultures are integrated and highly inclusive. Location advantage. Thailand is located in the center of southeast Asia. The capital Bangkok has become an important transportation hub in southeast Asia for air, road, railway and water. Education advantage. Low tuition and living expenses And study in Europe and the United States, low cost of study in Thailand, Thai university tuition fees of about 14000 yuan/year, the cost of living: 3-50000 yuan/year (tuition each year will make appropriate adjustments, the school website tuition standard shall prevail). In addition, Thailand's education visa is much easier than Europe and the United States, the application period is shorter, the application materials are relatively simple. Strong facultyThai teachers have high professional quality, and most colleges and universities will employ teachers with rich teaching experience and overseas study background. Foreign teachers have a high proportion of teachers and a strong faculty. Employment advantage. Thailand as south-east Asia's second-largest economy, as China area all the way and the process of asean integration deepening, Thailand will play a more important role in southeast Asia, together with China and Thailand bilateral trade is deepening. This will further expand the demand for talents, especially those who are proficient in Chinese, Thai and English.

\section{References}

[1] Lu haibo, Development of GuangXi Thai education in china-asean cooperation [J]. Nanning journal of occupational technology, January 2009.

[2] Wu chunlan, Study on the status and role of Thai education in studying abroad education in Yunnan province [J]. Qu Jing normal university, May 2015.

[3] Zhang Yuanyuan, Zhu Yaoshun, education of Yunnan university face the current situation and problems of international cooperation in running schools in southeast Asia. October 2016.

[4] Li Xiaoming. Study on intercultural adaptation of Chinese interns in Thailand and countermeasures -- a case study of students in Thailand from Guang Xi university from 2010 to 2011 [D]. Guangxi university, 2012.

[5] Liu Enlin. Innovation of intercollegiate cooperation and talent cultivation model in Chinese universities [D]. Shandong university, 2010.

[6] Yu D, Peng L. When does Inferring Reputation Probability Countervail Temptation in Cooperative Behaviors for the Prisoners' Dilemma Game? [J]. Chaos, Solitons \& Fractals, 2015, 78: 238-244. 